\title{
Common Mental Disorder among HIV Infected Individuals at Comprehensive HIV Care and Treatment Clinic of Debre Markos Referral Hospital, Ethiopia
}

\section{Selamawit Zewdu ${ }^{1 *}$ and Nurilign Abebe ${ }^{2}$}

${ }^{1}$ Department of Nursing, College of Medicine and Health Science, Debremarkos University, Ethopia

${ }^{2}$ Department of Public Health, College of Medicine and Health Science, Debremarkos University, Ethopia

\begin{abstract}
Introduction: The presence of HIVIAIDS increases the risk of development of mental disorders and the presence mental illness affects disease progression. The resulting co morbidity complicates help -seeking, diagnosis, quality of care provided, treatment and its outcomes, and adherence. Despite the fact that developing countries carry huge burden of both HIVIAIDS and mental illness, no data about the co-occurrence/link and factors associated is available in local setting. The aim of this study was to assess the prevalence of common mental disorder and associated factors among PLHA at Comprehensive HIV Care and Treatment Clinic of Debre Markos referral Hospital in 2013/2014. An institution-based cross sectional study with the Amharic version of the SRQ was conducted. Ethical clearance was obtained from Institutional Review Board of Debre Markos University and Informed consent was obtained.

Result: Mean age was 37.9 years \pm 10.05 years. Prevalence of CMD is found to be $24.3 \%$. Significant associations were found between CMD and past psychiatric illness, ART regimen, marital status, HIVIAIDS disclosure and perceived stigma.

Conclusion and recommendation: There was a significant burden of mental illness among HIV-infected individuals in this setting. It is important to note that the link between HIV care and treatment services and psychiatric service should strengthen. Hospital administrators must give better attention to inpatient mental health service including substance abuse treatment. Clinicians also should always assess HIV-infected subjects for depression, anxiety and other common mental disorders to ensure early detection and treatment.
\end{abstract}

Keywords: AIDS; Common mental disorder; HIV

\section{Introduction}

Among the non-communicable diseases, psychiatric illnesses especially CMD are the most prevalent psychiatric illnesses and are the most important cause of disability in low income countries accounting for $12 \%$ of the global burden of disease-a figure that is expected to rise to $15 \%$ by the year $2020[1,2]$.

In Ethiopia, mental illness is the leading non-communicable disorder in terms of burden. Indeed, in a predominantly rural area of Ethiopia, mental illness comprised $11 \%$ of the total burden of disease, with schizophrenia and depression included in the top ten most burdensome conditions, out-ranking HIV/AIDS [2]. These startling statistics show that mental illnesses have been overlooked as a major health priority in Ethiopia and other LMICs, and underscore the need for public health programs targeting mental illnesses [2].

People living with HIV are about twice more likely to experience mental health disorders especially CMDs like depression and anxiety than the general population which, in turn, impair their immune function, reduce their quality of life and adherence to treatment and contribute significantly to their premature deaths $[2,3]$.

There seem to be several reasons for this: firstly, the difficulty of living with a chronic, life-threatening and highly stigmatized illness; secondly the direct effects of HIV and some opportunistic infections on the brain and central nervous system; and thirdly the side effects of antiretroviral therapy can have mental, behavioral or neurological side-effects $[2,3,4]$. In other hand Substance use can have a two-fold relationship with HIV risk. Use of substances like alcohol, opioids, cocaine etc., can lead to disinhibition and unprotected sex with multiple partners [5]. On the other hand, a common risk factor in form of a personality attribute may underlie both alcohol use and high risk sexual behavior [6].

Common mental disorder (CMD) is a term used to describe a group of mental disorders that frequently occur in primary care patients. It includes symptoms of depression, anxiety and somatization the latter often indicated by repeated visits to health care practitioners without resolution of the problem $[7,8]$.

CMDs are not decreasing in the ART era, CMD prevalence is influenced by viral central nervous system pathology, concomitant psychosocial stressors and the nature of HIV as a life-threatening and stigmatized illness [3,9]. Many people with HIV experience a wide range of psychological and psychosocial issues throughout the experience of living with and adjusting to the disease. Difficulties may arise at every stage of infection including around the time of testing for HIV; when symptoms develop; receiving an AIDS diagnosis; beginning anti-HIV medication; and in terminal care [10].

${ }^{*}$ Corresponding author: Selamawit Zewdu, Department of Nursing, College of Medicine and Health Science, Debremarkos University, Debre Markos, Amhara 269, Ethopia, Tel: 251913139474; Fax: 2510587711764; E-mail: selaminana@ gmail.com;eaglezewdu@gmail.com

Received October 01, 2014; Accepted January 15, 2015; Published January 24 2015

Citation: Zewdu S, Abebe N (2015) Common Mental Disorder among HIV Infected Individuals at Comprehensive HIV Care and Treatment Clinic of Debre Markos Referral Hospital, Ethiopia. J AIDS Clin Res 6: 420. doi:10.4172/2155 6113.1000420

Copyright: ( 2015 Zewdu S, et al. This is an open-access article distributed under the terms of the Creative Commons Attribution License, which permits unrestricted use, distribution, and reproduction in any medium, provided the original author and source are credited. 
A paper reviewed on the mental health of HIV infected adults in Africa between 1994 and 2008 reported that about half of HIV-infected adults had some form of psychiatric disorder, with depression the most common problem $[11,12]$.

Prevalence of common mental disorders among HIV infected people in low income countries ranges from $82.6 \%$ in Mulago Hospital in Kampala, Uganda [13], 63\% in Ya oundé, Cameron [14], 57\% pregnant and HIV infected women in Tanzania [15], 56.7\% depression in North Central Nigeria [16], 46.4\% hospitals in oromia region Ethiopia [17], 43.9\% of depression in Mekele and Addigrat hospitals in Tigrie region Ethiopia [18], 38.3\% in Nigeria [19], 24\% done in Southern Uganda [20], 19\% in south Africa cape town [21] to $11.2 \%$ in Dilla Hospital in south region of Ethiopia [22].

Mental or psychological disorders often seems to be related the severity of HIV/AIDS, medications side effects, Younger age, higher viral load, the loss of health, a decrease in functioning, the deterioration of body integrity, anticipatory loss of life, Pain, poor family support and presence of AIDS in the spouse, cultural factors like stigma, relative lack of appropriate treatment facilities, poor access to the health care and low educational level could have significantly contributed $[23,24]$.

Undetected mental health and co-occurring conditions such as substance-related disorders can have a profound effect on adherence, clinic attendance, and quality of life, and can influence the progression of disease and high-risk behaviors that increase risk of HIV transmission $[5,25]$.

Addressing the mental health issues for people living with HIV (PLHIV) is central to a comprehensive approach to their care, support, and to design interventions and support services to address those needs $[5,23,26]$.

Despite the fact that sub-Saharan countries carry more than $90 \%$ of the burden of HIV/AIDS and studies reported that there is high prevalence of mental health disorders related to HIV CMDs often go undiagnosed and untreated in this population [27]. Also there is lack of studies about the interaction between HIV/AIDS and mental health [23].

There is no study done on the prevalence and factors associated with mental illness among PLHA in Amhara region and Debre Markos setting. This study attempts to bridge the gap by adding to the limited body of knowledge about the prevalence rate of mental illnesses and factors associated among HIV/AIDS infected patients in local setting.

\section{Methods}

\section{Study design, setting and period}

Institution based cross-sectional study design was used. The study took place between November to December 2013 at Debre Markos Referral Hospital, East Gojjam, Amhara, Ethiopia. The sample required for this study was determined by using single population proportion formula considering $95 \%$ confidence interval (CI), proportion of the CMD to be $46.7 \%$ from Study done in three hospitals in Oromia, Ethiopia [17], absolute precision to be $5 \%$ and $10 \%$ non-respondents. Participants who were 18 years and above, tested HIV positive, currently receiving HIV/AIDS care and able to give interview selected by systematic sampling method. Data collection and Measures After informed consent was maintained CMD was assessed through face to face interviews using interviewer-administered pre tested and Amharic version of the Self-Reporting Questionnaire (SRQ-20).

\section{The Self-Reporting Questionnaire (SRQ)}

SRQ is a Questionnaire contains 20 yes/no Questions developed by $\mathrm{WHO}$ and is a widely used instrument. It was designed for screening for the presence of symptoms of CMD in patients in primary health care settings [28]. It has been validated in sub-Saharan countries including Ethiopia the optimal cut-off for defining cases for CMD has also varied widely depending on the setting, community surveys or primary care. Even though varied cut-off points have been used cut-off point of $7 / 8$ is widely used [28]. So in this study cut off point 8 was used to screen respondents' symptom of common mental disorder. Crnbach's alpha for this sample was 0.931 .

\section{Cage AID}

Cut down, annoyance by criticism, guilty feeling and eye opener adapted to include drug use is a brief tool widely used to screen alcohol and drug abuse conjointly.

\section{Scoring}

Item responses on the CAGE questions are scored 0 for "no" and 1 for "yes" answers, with a higher score being an indication of problems. A total score of two or greater is considered clinically significant [29]. Medical data related to HIV/AIDS collected by reviewing Medical charts.

\section{Data analysis and interpretation}

The coded Data was checked, cleaned by entering into EPI data and analyzed with SPSS version 16 . To estimate the prevalence of common mental disorder, descriptive statistics, using frequencies, mean and standards deviation was used. Bivariate analysis was performed to determine each of these factors and how they are associated with a CMD. A $p<0.05$ was considered as statistically significant.

\section{Result}

Out of 422 questionnaires 412 were returned back with full response, this yielded the response rate $97.6 \%$. The age of the respondents ranged from 18 to 65 years; the mean age was 37.9 years ( \pm 10.05 years). From participants $58.3 \%$ was females and $83 \%$ of them were from urban areas. Majority $95.1 \%$ of the respondents follows orthodox Christian and $97.1 \%$ were Amhara by ethnicity. From 412 respondents $117(28.4$ $\%)$ was living alone. Two hundred thirty $(55.8 \%)$ of the participants earn less than 500 ETB (Table 1). 35\% of respondents since confirmed their HIV positive result 3 to 5 years back and the other $33.3 \%, 23.5 \%$ and $8 \%$ confirmed their result 6 to 8,1 to 2 and 9 to 11 years ago respectively. More than half of (68.4\%) of the study participants were on WHO stage I HIV/AIDS stage followed by $19 \%, 10.9 \%$, and $1.2 \%$ had stage III, stage II and stage IV respectively. The CD4 cell count ranged from 5 to $999 \mathrm{~mm}^{3} / \mathrm{dl}$ with mean value $435.4 \pm 2238.3$ and $355(86.2 \%)$ of respondents had a CD4 cell count greater than or equal to $200 \mathrm{~mm}^{3} / \mathrm{dl}$ ). Out of 412 participants 383 (93\%) were started ART (Table 2).

Forty one percent of the clients were taking antiretroviral drug regimen Tenofovir, Lamuvidine and Neverapine, 23.3\% was taking Zidovidine, Lamuvidine and Neverapine, $10 \%$ was taking Zidovidine, Lamuvidin and Efavirenz, 18.2\% was taking Tenofovir, Lamuvidine and Efavirenz and the remaining $7 \%$ was not taking anti-retroviral drug. Eighty percent of the respondents disclosed their HIV /AIDS status for their relatives. From those who started $34.5 \%$ of respondents were on ART for the past 3 to five years (Figure 1). $4.6 \%$ of the respondents had psychiatric diagnosis after knowing their HIV status confirmed by clinicians. 
Citation: Zewdu S, Abebe N (2015) Common Mental Disorder among HIV Infected Individuals at Comprehensive HIV Care and Treatment Clinic of Debre Markos Referral Hospital, Ethiopia. J AIDS Clin Res 6: 420. doi:10.4172/2155-6113.1000420

Page 3 of 6

\begin{tabular}{|c|c|c|c|}
\hline \multicolumn{2}{|l|}{ Variables } & \multirow{2}{*}{$\begin{array}{c}\text { Frequency }(\mathbf{n}=\mathbf{4 1 2}) \\
172\end{array}$} & \multirow{2}{*}{$\begin{array}{c}\% \\
41.5\end{array}$} \\
\hline \multirow{2}{*}{ Sex } & Male & & \\
\hline & Female & 240 & 58.3 \\
\hline \multirow{5}{*}{ Marital status } & Married and live together & 202 & 49.0 \\
\hline & Single & 48 & 11.7 \\
\hline & Divorced & 91 & 22.1 \\
\hline & Widowed & 65 & 15.8 \\
\hline & Married but separated & 6 & 1.5 \\
\hline \multirow{5}{*}{ Educational status } & Illiterate & 120 & 29.1 \\
\hline & Primary & 130 & 31.6 \\
\hline & Secondary & 115 & 27.9 \\
\hline & Diploma & 32 & 7.8 \\
\hline & Degree and above & 15 & 3.6 \\
\hline \multirow{3}{*}{ Religion } & "Orthodox Christian & 392 & 95.1 \\
\hline & Muslim & 13 & 3.2 \\
\hline & Protestant & 7 & 1.7 \\
\hline \multirow{3}{*}{ Ethnicity } & Amhara & 400 & 97.1 \\
\hline & Oromo & 3 & 0.7 \\
\hline & Tigre & 9 & 2.2 \\
\hline \multirow{5}{*}{ Job } & Government employed & 101 & 24.5 \\
\hline & Private employed & 29 & 7.0 \\
\hline & Self employed & 209 & 50.7 \\
\hline & Housewife & 66 & 16.0 \\
\hline & Unemployed & 7 & 1.7 \\
\hline \multirow{5}{*}{$\begin{array}{l}\text { Income } \\
\text { In Ethiopian birr }\end{array}$} & $<500$ & 230 & 55.8 \\
\hline & $500-1000$ & 78 & 18.9 \\
\hline & $1001-1500$ & 31 & 7.5 \\
\hline & $1501-2000$ & 39 & 9.5 \\
\hline & $>2000$ & 34 & 8.3 \\
\hline \multirow[t]{2}{*}{ Residency } & Rural & 70 & 17.0 \\
\hline & Urban & 342 & 83.0 \\
\hline
\end{tabular}

Table 1: Socio-Demographic Characteristics of HIV infected individuals at Debre Markos referral hospital, East Gojjam, Amhara, Ethiopia, December, 2013

\begin{tabular}{|l|c|c|c|}
\hline Variables & Frequency $\mathbf{n = 4 1 2}$ & $\%$ \\
\hline \multirow{4}{*}{ Date confirmed } & $\leq 2$ years ago & 97 & 23.5 \\
\cline { 2 - 4 } & 3-5 years ago & 145 & 35.2 \\
\cline { 2 - 4 } & $6-8$ years ago & 137 & 33.3 \\
\cline { 2 - 4 } & $9-11$ years ago & 33 & 8.0 \\
\hline \multirow{3}{*}{ WHO staging of HIVIAIDS } & Stage I & 282 & 68.4 \\
\cline { 2 - 4 } & Stage II & 45 & 10.9 \\
\cline { 2 - 4 } & Stage III & 80 & 19.4 \\
\cline { 2 - 4 } Last CD4 Cell Count & Stage IV & 5 & 1.2 \\
\hline \multirow{3}{*}{ Antiretroviral Drug Side Effect } & $\leq 435$ & 235 & 57.0 \\
\cline { 2 - 4 } & $>435$ & 177 & 43.0 \\
\cline { 2 - 4 } & Yes & 150 & 36.4 \\
\cline { 2 - 4 } & No & 233 & 56.6 \\
\hline \multirow{3}{*}{ Antiretroviral Drug Adherence } & Good & 29 & 7.0 \\
\cline { 2 - 4 } & Fair & 14 & 93.5 \\
\cline { 2 - 4 } & Poor & 11 & 2.7 \\
\hline
\end{tabular}

Table 2: HIVIAIDS Related Characteristics of HIV infected individuals at Comprehensive HIV Care and treatment clinic of Debre Markos referral hospital, East Gojjam, Amhara, Ethiopia, 2013

\section{Prevalence of common mental disorder}

Widely accepted Cut off point $\geq 8$ was used for detecting symptoms of CMD. From 412 HIV infected individuals 100 of them scores 8 and

more on SRQ. Prevalence of CMD was found to be $24.3 \%$ (Figure 2). At different cut of points prevalence of CMD was different. If lower cutoff points were used, the prevalence of mental distress would increase (Figure 3).

The most frequent cognitive symptom were loss of interest in things reported by $23.5 \%(n=97)$ and the most frequent anxiety symptoms were "feel worried, nervousness or tense" and "easily frightened" reported by $30.6 \%(n=126)$ and $26.9 \%(n=111)$ of respondents (Figure 4$)$.

Descriptive analysis indicated that $50(12.1 \%)$ of respondents were substance abuser (Table 3), $22.1 \%$ had suicidal ideation in the previous month, $6.3 \%$ had life time suicidal attempt and $1.5 \%$ of respondents attempt suicide in the previous month. The main reason for attempting was $34.8 \%$ due family conflict, $26.1 \%$ because of poverty, $13 \%$ due to mental illness. Majority of the attempters, $82.6 \%$ used poison as method of suicide. Nineteen (73.1\%) individuals attempt suicide once, 2 individuals (1.2\%) attempt tow times and 19.2\% (5 individuals) attempt

\section{Time on Antiretroviral drug therapy}

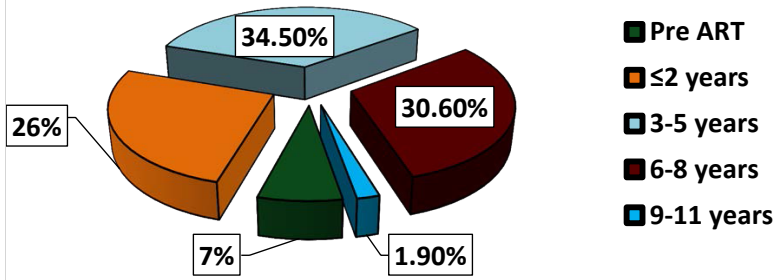

Figure 1: Description of participants based on time on antiretroviral drug therapy in Debre Markos referral hospital, East Gojjam, Amhara, Ethiopia 2013.

\section{Prevalence of CMD}

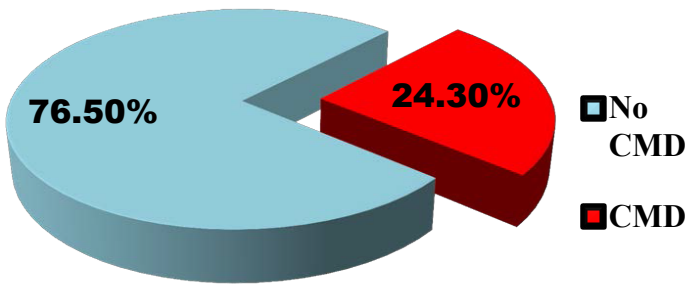

Figure 2: Prevalence of Common Mental Disorder among HIV infected individuals at Debre Markos referral hospital, Debre Markos, East Gojjam, Amhara, Ethiopia, 2013.

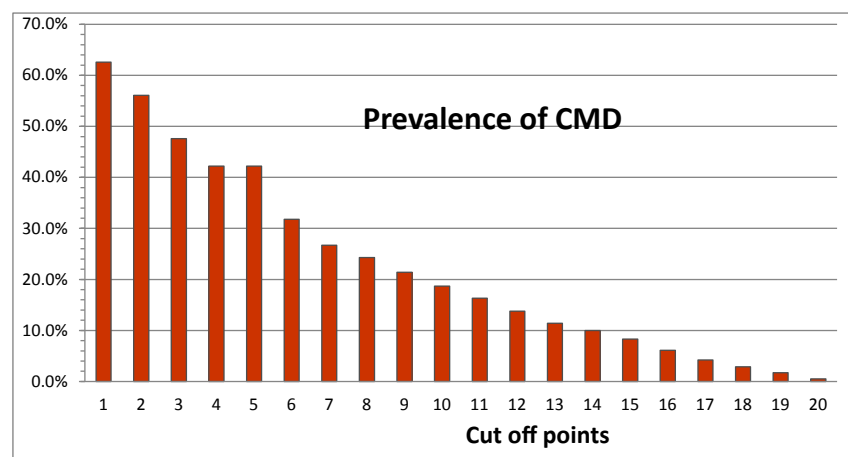

Figure 3: Prevalence of CMD with different cut off points of the SRQ-20. 


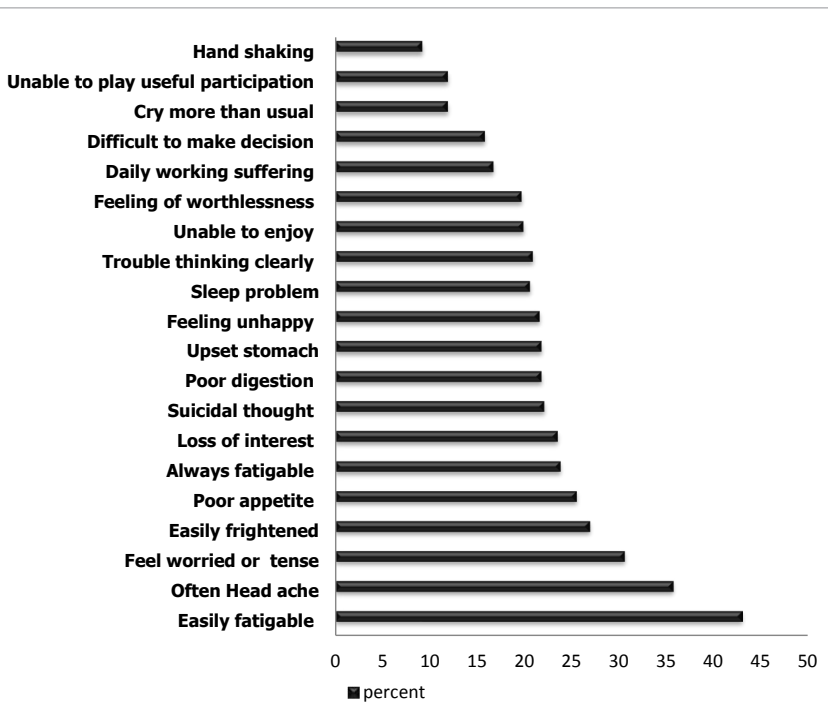

Figure 4: Prevalence of symptoms of CMD on SRQ -20.

\begin{tabular}{|c|c|c|c|}
\hline \multicolumn{2}{|l|}{ Variables } & \multirow{2}{*}{$\begin{array}{c}\text { Frequency } n=412 \\
56\end{array}$} & \multirow{2}{*}{\begin{tabular}{c|}
$\%$ \\
13.6
\end{tabular}} \\
\hline Psychiatric illness before & Yes & & \\
\hline HIV status confirmed & No & 356 & 86.4 \\
\hline \multirow{2}{*}{$\begin{array}{l}\text { Psychiatric illness after HIV } \\
\text { Status confirmed }\end{array}$} & Yes & 19 & 4.6 \\
\hline & No & 389 & 94.4 \\
\hline \multirow{3}{*}{$\begin{array}{l}\text { Family history of mental } \\
\text { illness }\end{array}$} & Yes & 22 & 5.3 \\
\hline & Unknown & 10 & 2.4 \\
\hline & No & 380 & 92.2 \\
\hline \multirow{3}{*}{$\begin{array}{l}\text { Family member death due } \\
\text { to HIV }\end{array}$} & Yes & 46 & 11.2 \\
\hline & No & 317 & 76.9 \\
\hline & Don't know & 49 & 11.9 \\
\hline \multirow{2}{*}{ Spouse death due to HIV } & Yes & 60 & 14.6 \\
\hline & No & 352 & 85.4 \\
\hline \multirow{3}{*}{ No of children } & Null & 109 & 26.5 \\
\hline & $1-2$ & 175 & 42.5 \\
\hline & $>2$ & 128 & 31.1 \\
\hline \multirow{4}{*}{ Child HIV status } & Positive & 42 & 10.2 \\
\hline & I don't know & 21 & 5.1 \\
\hline & Negative & 240 & 58.3 \\
\hline & No child & 109 & 26.5 \\
\hline \multirow{3}{*}{ Partner HIV status } & Positive & 170 & 41.3 \\
\hline & Unknown \& no partner & 106 & 25.7 \\
\hline & Negative & 136 & 33.0 \\
\hline \multirow{2}{*}{ Current Bereavement } & Yes & 34 & 8.3 \\
\hline & No & 378 & 91.7 \\
\hline
\end{tabular}

Table 3: Family History and stressful life event at ART clinic of Debre Markos referral hospital, East Gojjam, Amhara, Ethiopia, 2013

more than twice. Ten patients (2.4\%) had family history of attempted suicide and $1.5 \%$ (6 individuals) had a family member died by suicide (Table 4).

\section{Factors associated with common mental disorder}

Binary Logistic regression was used to test association between variables. On bivariate analysis the factors within $\mathrm{p}<0.3$ were entered to multivariate logistic analysis to control for possible confounders and $p<0.05$ was taken as a level of significance. Factors significantly associated with CMD were marital status, ART regimen perceived,

\begin{tabular}{|c|c|c|c|}
\hline \multicolumn{2}{|l|}{ Variables } & Frequency $n=412$ & $\%$ \\
\hline \multirow{2}{*}{ Living condition } & Family & 295 & 71.6 \\
\hline & Alone & 117 & 28.4 \\
\hline \multirow{5}{*}{ Perceived Social support } & Excellent & 108 & 26.2 \\
\hline & Very good & 143 & 34.7 \\
\hline & Good & 100 & 24.3 \\
\hline & Fair & 25 & 6.1 \\
\hline & Low & 36 & 8.7 \\
\hline \multirow{5}{*}{ Perceived religiosity } & Excellent & 83 & 20.1 \\
\hline & Very good & 209 & 50.7 \\
\hline & Good & 97 & 23.5 \\
\hline & Fair & 9 & 2.2 \\
\hline & Low & 14 & 3.4 \\
\hline \multirow{2}{*}{ Perceived stigma and discrimination } & Yes & 82 & 19.9 \\
\hline & No & 330 & 80.1 \\
\hline \multirow{2}{*}{ Member of HIV association } & Yes & 120 & 29.1 \\
\hline & No & 292 & 70.9 \\
\hline \multirow{2}{*}{ Current Substance use } & Yes & 40 & 9.7 \\
\hline & No & 372 & 90.3 \\
\hline \multirow{5}{*}{ Type of substance } & Alcohol & 33 & 8.0 \\
\hline & Chat & 4 & 1.0 \\
\hline & Hashish & 1 & 0.2 \\
\hline & $\begin{array}{l}\text { Combine } \\
\text { use }\end{array}$ & 2 & 0.5 \\
\hline & Non user & 372 & 90.3 \\
\hline
\end{tabular}

Table 4: Social Support and Substance Related Characteristics of the Respondents at ART clinic of Debre Markos referral hospital, East Gojjam, Amhara, Ethiopia, 2013.

perceived stigma, past psychiatric illness and HIV disclosure (Table 5).

When compared to patients taking AZT-3TC-NVP (1c) ART drugs, those who was taking ART regimen TDF-3TC- EFV (1f) reduced risk of getting CMD by 0.05 with adjusted ratio of $(0.0595 \% \mathrm{CI}(0.01,0.24))$. Those Individuals who perceived stigma due to their HIV/AIDS status were 4.5 times more likely to suffer from common mental disorder than who did not perceived (AOR=10.1, 95\% CI $(5.91,17.5)$ ). PLHA who disclosed there HIV status reduced risk of CMD by 0.16 times than who didn't disclosed (AOR=0.16, $95 \%$ CI $(0.03,0.73)$ ). Patients who had past psychiatric history were 5 times more likely to had CMD. $(\mathrm{AOR}=5.16,95 \% \mathrm{CI} 1.05,25.1)$ ).

\section{Discussion}

Prevalence of CMD was found to be $24.3 \%$ which was lower than a study from three hospitals in Oromia region, Ethiopia which was $46.7 \%$ (18) the reason for this inconsistency may be due to different tools they used (Kessler 10) with lower cut of point (6/7) to measure CMD.

It is also lower than studies from Uganda $82.6 \%$ [13] and Nigerian studies which explored 56.7\% [16] and 38.3\% [19] prevalence of CMD disorder among PLHA. This may be due to those researchers tried to detect many psychiatric co-morbidities beyond depression and anxiety but in this study SRQ screened CMD signs and symptoms mainly anxiety, depression and psychosomatic symptoms. Also socio-cultural differences may result the difference.

It is also lower than studies from Albanian study that explored depression and anxiety prevalence as $82.3 \%$ and $62.3 \%$ [30], North Central Nigeria in 2013 56.7\% [16], Yaoundé, Cameron which revealed $63 \%$ of individuals had moderate depression [28]. A study from three hospitals in Tigray region which revealed $43.9 \%$ of patients were 


\begin{tabular}{|c|c|c|c|c|c|}
\hline & & COR & $95 \% \mathrm{Cl}$ & AOR & $95 \% \mathrm{Cl}$ \\
\hline \multirow{4}{*}{ Marital status } & Married/live together & 1 & & 1 & \\
\hline & Single & 1.96 & $(0.06,3.97)$ & 0.22 & $(0.005,11.54)$ \\
\hline & Widowed & 1.46 & $(0.80,2.63)$ & 1.89 & $(0.66,5.38)$ \\
\hline & Divorced /separated & 2.20 & $(1.20,4.03)$ & 7.43 & $(2.11,21.2)^{\star *}$ \\
\hline \multirow{4}{*}{ ART Regimen } & AZT-3TC-NVP (1c) & 1 & 1 & 1 & 1 \\
\hline & TDF-3TC- NVP (1e) & 0.66 & $(0.38,1.15)$ & 0.41 & $(0.15,1.14)$ \\
\hline & TDF-3TC- EFV (1f ) & 0.48 & $(0.23,0.99)$ & 0.05 & $(0.01,0.24)^{\star * *}$ \\
\hline & AZT-3TC- EFV (1d) & 0.29 & $(0.10,0.81)$ & 0.39 & $(0.06,2.29)$ \\
\hline \multirow{2}{*}{ HIV disclosure } & Yes & 0.41 & $(0.24,0.69)$ & 0.16 & $(0.03,0.73)^{*}$ \\
\hline & No & 1 & & 1 & \\
\hline \multirow{2}{*}{$\begin{array}{c}\text { Perceived } \\
\text { Stigma }\end{array}$} & Yes & 10.18 & $(5.91,17.5)$ & 7.7 & $(2.53,18.8)^{\star \star \star}$ \\
\hline & No & 1 & & 1 & \\
\hline \multirow{2}{*}{$\begin{array}{c}\text { Past psychiatric } \\
\text { history }\end{array}$} & Yes & 4.34 & $(2.13,8.81)$ & 5.16 & $(1.05,20.1)^{*}$ \\
\hline & No & 1 & & 1 & \\
\hline
\end{tabular}

* Significance at $P$ value $<0.05,{ }^{* *}$ Significance at $p$ value $<0.01,{ }^{* * *}$ Significance at $p$ value $<0.001$

Table 5: Multivariate Association Between Independent Variables and CMD Among PLHA at ART Clinic of DMRH, East Gojjam, Amhara, Ethiopia, 2013.

depressed [18]. The reason for these discrepancies may be due to the above mention studies focus only on depression and also tool they used.

However the result is higher than another study in Dilla hospital in Ethiopia [22] which were $11.2 \%$ and South Africans study which found $19 \%$ psychiatric morbidity among PLHA [21]. This difference may be due to different tool that Hospital Anxiety and Depression Scale in Ethiopian and South African researchers used diagnostic tool MINI but this study used screening tool.

Prevalence of CMD also higher than community studies among working adults in Addis Ababa, Ethiopia which was 17.7\% [31] and rural Butajra with $17 \%$ prevalence [32]. The difference might be due to co morbid physical illness (HIV/AIDS).

But this result was in line with south Ugandans [20] study which found as $24 \%$ of CMD/depression and study from Ethiopia which found $24.5 \%$ of CMD among samples with malaria in primary health care [33].

The most frequent cognitive symptom reported by participants was loss of interest in things (23.5\%). This result was similar to study done among PHC patients in Ethiopia [33].

In this study factors associated with CMD were divorced Martial status, Tenofovir-lamuvidine-Efavirenz ART Regimen, HIV disclosure, past psychiatric history and Perceived stigma.

Individuals reported perceived stigma was 4.5 times more likely to suffer by CMD; this finding was supported by study done in Oromia region, Ethiopia [17,23,24].

When compared to patients Zidovidine-lamuvidine - neverapine ART drugs, those who was taking ART regimen Tenofovir-lamuvidine - Efavirenz reduced risk of getting CMD by 0.05 , this finding was inconsistent with literatures which reported that Efavirenz containing regimens are commonly cause psychiatric symptoms [11]. This needs further research.

PLHA who were disclosed their HIV status reduced risk of CMD by 0.16 times than who didn't disclosed. This is may be due to emotional and material support the patient gain from their relatives as a result of their disclosure. This result is in line with many research findings [11,16,34].

Those who had divorced marital status were seven times more likely to get CMDs than married one this may be due to the lack of emotional support from partner and this finding is supported by findings from
South Africa [21]. Patients who had past psychiatric history been 5 times more likely to had CMD this is in line with findings from many studies [27].

\section{Limitation of study}

- Since it is a cross -sectional study, we couldn't determine causal links between CMD and some important variables.

- Social support, stigma and religiosity were assessed by single questions but it was good if standard questionnaire were used.

\section{Conclusion}

- Even though prevalence of CMD in this setting found to be lower than many literatures searched, this result indicated that there was a significant burden of mental illness and still under diagnosed among HIV-infected individuals.

- Factors associated to CMD were divorced Martial status, If (TDF-3TC-EFV) ART Regimen, HIV disclosure, Past psychiatric history and Perceived Stigma.

- Factors like HIV/AIDS stage CD4 count, partner and child HIV/AIDS status, gender, age, perceived religiosity and grief were not associated with CMD in multivariate analysis.

\section{Recommendations}

\section{Hospital administration}

- Should strengthen the link between HIV care and treatment services and psychiatric service.

- Must give better attention to inpatient mental health service including substance abuse treatment.

\section{Clinicians}

- Even though Clinicians already screening HIV-infected patients for mental illness, they should do it always especially for CMDs like depression and anxiety to ensure early detection and treatment.

\section{Researchers}

- The link between, ART regimen and other factors should study independently by different designs other than cross sectional study. 
Citation: Zewdu S, Abebe N (2015) Common Mental Disorder among HIV Infected Individuals at Comprehensive HIV Care and Treatment Clinic of Debre Markos Referral Hospital, Ethiopia. J AIDS Clin Res 6: 420. doi:10.4172/2155-6113.1000420

\section{References}

1. WHO (2001) The world health report 2001 - Mental Health: new understanding, new hope. Geneva: World Health Organization.

2. Federal Democratic Republic of Ethiopia Ministry of Health. National Mental Health Strategy 2012/13 - 2015/16.

3. WHO HIVIAIDS and mental health Report by the Secretariat 20 November 2008.

4. Annabelle South, Nathaniel Chishinga, Helen Weiss (2011) Screening for the mental health needs of people living with HIV. Evidence for Action Policy Briefi $\mathrm{ng}$.

5. Gutmann, Mary, Andrew Fullem (2009) Mental Health and HIVIAIDS. Arlington, VA: USAID|AIDSTAR- ONE PROJECT, Task Order 1

6. USAID and WHO, Global summary of the AIDS epidemic 2012.

7. Lazarus R, Freeman M (2009) Primary-Level Mental Health Care for Common Mental Disorder in Resource-Poor Settings: Models \& Practice - A Literature Review. Sexual Violence Research Initiative, Medical Research Council, Pretoria, South Africa, 5.

8. Patel V, Araya R, Chowdhary N, King M, Kirkwood B, et al. (2008) Detecting common mental disorders in primary care in India: a comparison of five screening questionnaires. Psychol Med 38: 221-228.

9. Ciesla JA, Roberts JE (2001) Meta-analysis of the relationship between HIV infection and risk for depressive disorders. Am J Psychiatry 158: 725-730.

10. Global Initiative on Psychiatry (2006) Double stigma, double challenge: Mental health and HIV/AIDS in Central and Eastern Europe and the Newly Independent States: an advocacy and information document.

11. René Brandt (2008) The mental health of people living with HIVIAIDS in Africa: A systematic review. African Journal of AIDS Research 8: 123-133.

12. UNAIDS (2004b) The changing HIVIAIDS epidemic in Europe and Central Asia. CP 102, UNAIDS, Geneva, Switzerland.

13. Harry P, Jed B, Emilio O (2005) Psychiatric disorders in HIV-positive individuals in urban Uganda. Psychiatric Bulletin 29: 455-458.

14. L'akoa RM, Noubiap JJ, Fang Y, Ntone FE, Kuaban C (2013) Prevalence and correlates of depressive symptoms in HIV-positive patients: a crosssectional study among newly diagnosed patients in Yaoundé, Cameroon. BMC Psychiatry 13: 228

15. Antelman G, Kaaya S, Wei R, Mbwambo J, Msamanga GI, et al. (2007) Depressive symptoms increase risk of HIV disease progression and mortality among women in Tanzania. J Acquir Immune Defic Syndr 44: 470-477.

16. Shittu RO, Issa BA, Olanrewaju GT, Mahmoud AO, Odeigah LO, et al. (2013) Prevalence and correlates of depressive disorders among people living with hiv/aids, in north central nigeria. J AIDS Clin Res 4: 251.

17. Deribew A, Tesfaye M, Hailmichael Y, Apers L, Abebe G, et al. (2010) Common mental disorders in TB/HIV co-infected patients in Ethiopia. BMC Infect Dis 10: 201.

18. Haftu Berhe, Alemayehu Bayray (2013) Prevalence of depression and associated factors among people living with hiv/aids in tigray, north ethiopia: a cross sectional hospital based study. IJPSR 4: 765-775.

19. Sulyman D, Abiodun OA, Yussuf AD (2013) Detection of psychiatric disorders by physicians attending to people living with hiv/aids in a nigeria university teaching hospital. Journal of Biology, Agriculture and Healthcare 3: 92-97.

20. Nakimuli-Mpungu E, Mojtabai R, Alexandre PK, Katabira E, Musisi S, et al. (2012) Cross-cultural adaptation and validation of the self-reporting questionnaire among HIV+ individuals in a rural ART program in southern Uganda. HIV AIDS (Auckl) 4: 51-60.

Citation: Zewdu S, Abebe N (2015) Common Mental Disorder among HIV Infected Individuals at Comprehensive HIV Care and Treatment Clinic of Debre Markos Referral Hospital, Ethiopia. J AIDS Clin Res 6: 420. doi:10.4172/21556113.1000420
21. Myer L, Smit J, Roux LL, Parker S, Stein DJ, et al. (2008) Common menta disorders among hiv-infected individuals in south africa: prevalence, predictors, and validation of brief psychiatric rating scales. AIDS Patient Care STDS 22 $147-158$.

22. Tesfaye SH, Bune GT (2014) Generalized psychological distress among HIVinfected patients enrolled in antiretroviral treatment in Dilla University Hospital Gedeo zone, Ethiopia. Glob Health Action 7: 23882.

23. World Health Organization (2008) Mental health \& HIVIAIDS therapy series. Geneva, World Health Organization

24. Florence B, Rachel T, Christine C (2005) HIVIAIDS and Mental Health. HNP discussion paper.

25. Bruce A, Hanson S, Zaam S (2010) Mental, neurological, and substance use disorders in sub-saharan africa: reducing the treatment gap, increasing quality of care.

26. Collins PY, Holman AR, Freeman MC, Patel V (2006) What is the relevance of mental health to HIVIAIDS care and treatment programs in developing countries? A systematic review. AIDS 20: 1571-1582.

27. Prabha S Chandra, Geetha Desai, Sanjeev Ranjan (2005) HIV \& psychiatric disorders. Indian J Med Res 121: 451-467.

28. Rafael Youngmann, Nelly Zilber, Fikre Workneh, Robert Giel (2008) Psychiatric Screening Instrument Adapting the SRQ for Ethiopian Populations: A CulturallySensitive. Transcult Psychiatry 45: 566.

29. Broun RL, Rounds LA (1995) Conjoint screening questionarea for alchol and other drugs abuse: criterion validity in a primary care practice. Wis med j 94 135-140.

30. Shane D Morrison, Vilson H Banushi, Clea Sarnquist, Valbona H. Gashi, Lars Osterberg, et al. (2011) Levels of self-reported depression and anxiety among HIV-positive patients in Albania: a cross-sectional study. Croat Med J 52: 622627.

31. Bizu Gelaye, Seblewengel Lemma, Negussie Deyassa, Yonas Bahretibeb, Markos Tesfaye, et al. (2012) Prevalence and correlates of mental distress among working adults in ethiopia. Clinical Practice and Epidemiology in Mental Health 8: 126-133.

32. Alem A, Kebede D, Woldesemiat G, Jacobsson L, Kullgren G (1999) The prevalence and socio-demographic correlates of mental distress in Butajira, Ethiopia. Acta Psychiatr Scand Suppl 99: 48-55.

33. Tesfaye M, Hanlon C, Tessema F, Prince M, Alem A (2014) Common Mental Disorder Symptoms among Patients with malaria attending primary care in ethiopia: A cross-sectional survey. PLoS ONE 9: e108923.

34. Adewuya AO, Afolabi MO, Ola BA, Ogundele OA, Ajibare AO, et al. (2007) Disorders among the HIV-positive population in Nigeria: A control study. J Psychosom Res 63: 203-206.

Submit your next manuscript and get advantages of OMICS Group submissions

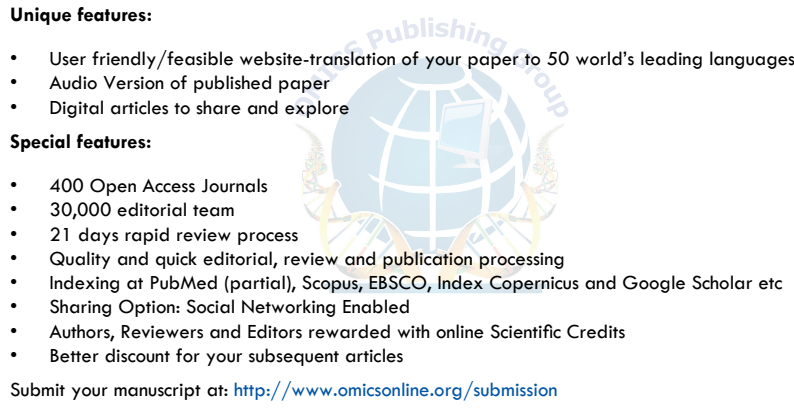

